\title{
Effects of Large Area Liquid Lithium Limiters on Spherical Torus Plasmas
}

R. Kaita, R. Majeski, M. Boaz, P. Efthimion, G. Gettelfinger, T. Gray, D. Hoffman, S. Jardin, H. Kugel, P. Marfuta, T. Munsal, D. Neumeyer, S. Raftopoulos, $V$. Soukhanovskii, J. Spaleta, G. Taylor, J. Timberlake, R. Woolley, L. Zakharov, M. Finkenthal, D. Stutman, L. Delgado-Aparcicio, R.P. Seravdarian, G. Antar, r. Doerner, S. Luckhardt, M. Baldwin, R.W. Conn, R. Maingi, M. Menon, R. Causey, D. Buchenauer, M. Ulrickson, B. Jones, $D$. Rodgers

U.S. Department of Energy

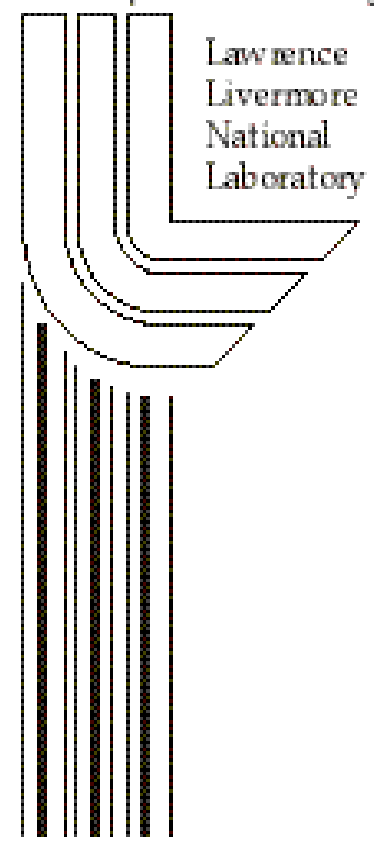

This article was submitted to the $16^{\text {th }}$ International Conference on Plasma Surface Interactions, Portland, Maine, May 24-28, 2004

\section{May 2004}




\section{DISCLAIMER}

This document was prepared as an account of work sponsored by an agency of the United States Government. Neither the United States Government nor the University of California nor any of their employees, makes any warranty, express or implied, or assumes any legal liability or responsibility for the accuracy, completeness, or usefulness of any information, apparatus, product, or process disclosed, or represents that its use would not infringe privately owned rights. Reference herein to any specific commercial product, process, or service by trade name, trademark, manufacturer, or otherwise, does not necessarily constitute or imply its endorsement, recommendation, or favoring by the United States Government or the University of California. The views and opinions of authors expressed herein do not necessarily state or reflect those of the United States Government or the University of California, and shall not be used for advertising or product endorsement purposes.

This is a preprint of a paper intended for publication in a journal or proceedings. Since changes may be made before publication, this preprint is made available with the understanding that it will not be cited or reproduced without the permission of the author.

This report has been reproduced directly from the best available copy.

Available to DOE and DOE contractors from the

Office of Scientific and Technical Information

P.O. Box 62, Oak Ridge, TN 37831

Prices available from (423) 576-8401

http: / / apollo.osti.gov/bridge/

Available to the public from the National Technical Information Service

U.S. Department of Commerce 5285 Port Royal Rd., Springfield, VA 22161 http:/ / www.ntis.gov/

OR

Lawrence Livermore National Laboratory Technical Information Department's Digital Library http:/ / www.llnl.gov/tid/Library.html 


\section{Effects of large area liquid lithium limiters on spherical torus plasmas}

R. Kaita ${ }^{a}{ }^{*}$ R. Majeski, ${ }^{a}$ M. Boaz, ${ }^{a}$ P. Efthimion,,${ }^{a}$ G. Gettelfinger,,${ }^{a}$ T. Gray, ${ }^{a}$ D. Hoffman, ${ }^{a}$

S. Jardin, ${ }^{a}$ H. Kugel,, P. Marfuta, ${ }^{a}$ T. Munsat, ${ }^{a}$ C. Neumeyer, ${ }^{a}$ S. Raftopoulos, ${ }^{a}$

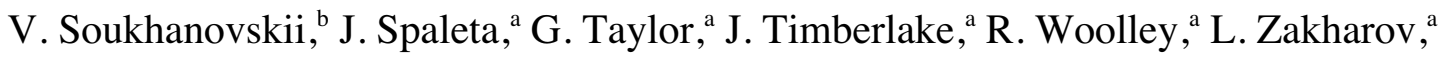

M. Finkenthal, ${ }^{\mathrm{c}}$ D. Stutman, ${ }^{\mathrm{c}}$ L. Delgado-Aparicio,${ }^{\mathrm{c}}$ R. P. Seraydarian, ${ }^{\mathrm{d}}$ G. Antar, ${ }^{\mathrm{d}}$

R. Doerner, ${ }^{\mathrm{d}}$ S. Luckhardt, ${ }^{\mathrm{d}}$ M. Baldwin, ${ }^{\mathrm{d}}$ R. W. Conn, ${ }^{\mathrm{d}}$ R. Maingi, ${ }^{\mathrm{e}}$ M. Menon,

R. Causey, ${ }^{\mathrm{f}}$ D. Buchenauer, ${ }^{\mathrm{f}}$ M. Ulrickson, ${ }_{\mathrm{f}}^{\mathrm{f}}$ B. Jones, ${ }^{\mathrm{f}}$ D. Rodgers ${ }^{\mathrm{g}}$

${ }^{a}$ Princeton Plasma Physics Laboratory, Princeton, NJ

${ }^{b}$ Lawrence Livermore National Laboratory, Livermore, CA

${ }^{c} J o h n s$ Hopkins University, Baltimore, MD

${ }^{d}$ University of California at San Diego, La Jolla, CA

${ }^{e}$ Oak Ridge National Laboratory, Oak Ridge, TN

${ }^{f}$ Sandia National Laboratories, Albuquerque, NM

${ }^{g}$ Drexel University, Philadelphia, $P A$

PACS: 28.52.Fa, 52.25.Vy, 52.40.Hf, 52.55Fa

JNM keywords: First Wall Materials, Fusion Reactor Materials, Impurities, Liquid Metals,

Plasma-Materials Interaction

PSI-16 keywords: Liquid metal, Lithium, Particle Control, Recycling, Wall Pumping

*Corresponding author address: Princeton Plasma Physics Laboratory, P. O. Box 451,

Princeton, NJ 08543 USA

*Corresponding author e-mail: kaita@pppl.gov

Presenting author: $R$. Kaita

Presenting author e-mail: kaita@pppl.gov 


\begin{abstract}
Use of a large-area liquid lithium surface as a first wall has significantly improved the plasma performance in the Current Drive Experiment-Upgrade (CDX-U) at the Princeton Plasma Physics Laboratory. Previous CDX-U experiments with a partially-covered toroidal lithium limiter tray have shown a decrease in impurities and the recycling of hydrogenic species. Improvements in loading techniques have permitted nearly full coverage of the tray surface with liquid lithium. Under these conditions, there was a large drop in the loop voltage needed to sustain the plasma current. The data are consistent with simulations that indicate more stable plasmas having broader current profiles, higher temperatures, and lowered impurities with liquid lithium walls. As further evidence for reduced recycling with a liquid lithium limiter, the gas puffing had to be increased by up to a factor of eight for the same plasma density achieved with an empty toroidal tray limiter.
\end{abstract}




\section{Introduction}

The search for suitable materials to be used as a first wall is a major challenge for fusion reactors. Liquid metals have great potential as a solution to this problem for several reasons.[1] First, liquid walls can eliminate erosion as an issue, since they are continuously renewed. This same characteristic will substantially reduce activated waste, and permit high heat handling. Furthermore, liquid lithium walls can result in significant physics advantages by providing a low recycling plasma boundary. Flat temperature profiles are expected under such conditions, for example, and the resulting elimination of electron conduction losses will lead to novel, stable confinement regimes.[2]

To explore the issues related to liquid lithium surfaces in a magnetic confinement device, experiments were first performed with a toroidally-local limiter[3,4] on the Current Drive Experiment-Upgrade (CDX-U) at the Princeton Plasma Physics Laboratory. The CDX-U device is a spherical torus with a major radius of $34 \mathrm{~cm}$ and a minor radius of $22 \mathrm{~cm}$. The toroidal field on axis is $2.2 \mathrm{kG}$. Central electron temperatures are about $100 \mathrm{eV}$, and central densities are approximately $6 \times 10^{-19} \mathrm{~m}^{-3}$. The toroidally-local limiter provided information about the conditioning requirements of liquid lithium surfaces and the behavior of liquid lithium in the presence of spherical torus fields. Its limited surface area $\left(30 \mathrm{~cm}^{2}\right)$, however, did not have a significant effect on CDX-U plasma performance.

To investigate the feasibility of large area liquid lithium surfaces, a fully-toroidal liquid lithium limiter was installed in CDX-U. This increased the liquid lithium plasma-facing surface area to $2000 \mathrm{~cm}^{2}$ on the fully-toroidal limiter. The toroidal limiter tray is shown 
in Fig. 1. It consists of two $10 \mathrm{~cm}$ wide, $0.64 \mathrm{~cm}$ deep stainless steel halves that are centered at a radius of $34 \mathrm{~cm}$. Each half is isolated from the vacuum vessel with boron nitride insulators on top of adjustable supports. An insulator also provides a break in the toroidal current path across the two halves. Electrical feedthroughs permit the tray to be externally grounded, or used as an electrode during glow discharge cleaning (GDC). Heaters beneath the tray provide temperature control up to 500 degrees $\mathrm{C}$, and heat shields protect the center stack and the bottom of the vacuum vessel.

\section{Liquid lithium effects on plasma fueling and recycling}

Past attempts at tray filling in CDX-U involved placing solid cylinders of lithium at several toroidal locations using a vacuum transfer apparatus. The tray temperature was then raised above the melting point of the lithium. Uniform distribution was not achieved, as the cylinders deformed but did not lose the coatings that still formed during the loading process. Enough molten lithium did emerge from the cylinders, however, to cover about half of the toroidal limiter tray. Even with such restricted coverage, discharges limited on this surface showed a reduction in the recycling of hydrogenic species and a lowering of impurity levels.[5]

An improved loading technique was developed by collaborators at the University of California at San Diego. The lithium was first liquefied in two reservoirs attached to loading tubes that passed through the CDX-U vacuum vessel. The limiter tray was heated to 500 degrees $\mathrm{C}$ under an argon atmosphere, and the lithium was injected into the two halves of tray. The high temperature was needed to dissolve any coatings on the stainless 
steel tray surface at the point of contact with the liquid lithium that might inhibit its flow. The argon provided a buffer that limited the coating of windows due to the evaporating lithium. The new filling method resulted in nearly full coverage of the $2000 \mathrm{~cm}^{2}$ tray surface with liquid lithium. As shown in Fig. 2, the lithium surface was highly reflective, and did not have the coating that was present during the tray loading with solid lithium.

With this increase in the liquid lithium limiter surface area, a clear effect on the plasma density was observed. For discharges limited by the empty toroidal tray, the recycling was sufficient to maintain the plasma density with only a prefill gas puff (Fig. 3). However, about 5 to 8 times this amount had to be introduced during liquid lithium limiter discharges to approach the same density (Fig. 4). This result is consistent with spectroscopic measurements of the deuterium-alpha emission. A detector viewing the center stack through a $656.1 \mathrm{~nm}$ interference filter shows the virtual disappearance of the signal for those discharges with a liquid lithium limiter (Fig. 5).

\section{Plasma profile modification, current drive, and heating}

There is also evidence for profile changes in plasmas with liquid lithium limiters. Much higher loop voltages were required to sustain plasmas that had a high recycling limiter. While such plasmas needed a loop voltage of $2 \mathrm{~V}$ or greater, liquid lithium limiter discharges were maintained with a loop voltage as low as $0.5 \mathrm{~V}$. Modeling with the Tokamak Simulation Code (TSC) [6] suggests a drop in the internal inductance by about factor of two in liquid lithium limiter discharges. This is consistent with broader and 
more stable current profiles, which is a key theoretical prediction of for tokamaks with lithium walls.[2]

Measurements of the soft X-ray emission suggest that a peak temperature cannot exceed 100 to $150 \mathrm{eV}$ in liquid lithium limiter plasmas. With this as a constraint on the TSC calculations, the modeling indicates a very low effective charge $\left(\mathrm{Z}_{\text {eff }}\right)$. This is supported by spectroscopic measurements of impurities, where a dramatic reduction in the oxygen emission at $441.6 \mathrm{~nm}$ is observed (Fig. 6).

The segregation of the visible emission data reflects the consistently higher plasma currents achieved in liquid lithium limiter discharges. Maximum currents before filling the tray with liquid lithium were between 60 and $65 \mathrm{kA}$, while currents in the $85-90 \mathrm{kA}$ range were obtained with a liquid lithium limiter. The Ohmic heating system is a capacitor bank power supply that is not feedback controlled, so higher plasma currents indicate better confinement.

The improved performance is also reflected in the ion temperatures, as deduced from the Doppler broadening of a visible carbon line (CIV). For an empty tray limiter discharge with a plasma current of $58 \mathrm{kA}$, the ion temperature was $25 \mathrm{eV}$. At the same plasma current, a liquid lithium limiter discharge had a measured ion temperature of $64 \mathrm{eV}$.

\section{Outstanding issues and future plans}


A major result of the CDX-U experiments has been the dramatic increase in the particle pumping in the presence of the liquid lithium limiter. To improve the fueling efficiency, a supersonic gas injector (SGI)[7] is being developed. A preliminary characterization of the nozzle with a pressure transducer array indicates the production of a collimated gas jet over a range of Mach 2 to 5, with a divergence half-angle of 6 degrees. Initial tests on CDX-U suggest a sixty percent increase in the line-averaged density. Rate of rise measurements, however, show a higher pressure with the SGI when compared with the standard gas puffer for the same pulse duration. More work is thus needed to differentiate between the effect of the flow rate of the gas rate compared to its speed.

The next step in liquid lithium wall research at the CDX-U facility involves extensive modifications that will result in a new device called the Lithium Tokamak Experiment (LTX). The salient feature of LTX will be a new conformal copper shell into the CDX-U vacuum vessel. This shell will have a lithium coating evaporated onto its inner wall, and it will be kept above the melting point of lithium to insure that the plasma faces a liquid surface. Based on the CDX-U observations of the large reduction in recycling in the presence of liquid lithium walls, the temperature and density profiles, transport, current profiles, and beta limit are expected to be profoundly changed in LTX plasmas. The goal is to demonstrate the signature prediction of modeling for a tokamak with nonrecycling walls, i. e., the development of a broad electron temperature profile with $\mathrm{T}_{\mathrm{e}}($ edge $) / \mathrm{T}_{\mathrm{e}}$ (average) $\geq 1$, for the first time in LTX.

\section{Acknowledgement}


This work was supported by the US Department of Energy in part under Contract DEAC02-76-CHO3073.

This work was performed under the auspices of the U.S. Department of Energy by the University of California, Lawrence Livermore National Laboratory under Contract No. W-7405-Eng-48.

\section{References}

[1] M. A. Abdou et al., Fus. Eng. Des. 54 (2001) 181.

[2] S. I. Krasheninnikov, L. E. Zakharov, G. E. Pereverzev, Phys. Plasmas 10 (2003) 1678.

[3] G. Antar et al., Fus. Eng. Des. 60 (2002) 157.

[4] R. Kaita et al., Fus. Eng. Des. 61-62 (2002) 217.

[5] R. Majeski et al., J. Nucl. Mater. 313-316 (2003) 625.

[6] S. C. Jardin, N. Pomphrey, J. DeLucia, J. Comp. Phys. 66 (1987) 481.

[7] V. A. Soukhanovskii, H. W. Kugel, R. Kaita, R. Majeski, A. L. Roquemore, G. Gettelfinger, T. Gray, Proc. $15^{\text {th }}$ Top. Conf. High Temp.Plasma Diagnostics, submitted for publication in Rev. Sci. Instrum.

\section{Figure Captions}

Fig. 1 - Toroidal tray limiter in CDX-U vacuum vessel prior to liquid lithium fill. Heat shields can be seen below the tray and on the center stack.

Fig. 2 - Liquid lithium in toroidal tray limiter. Note the reflection on the surface of the vertical tube containing magnetic sensors near the center of the photograph.

Fig. 3 - Time evolution of the line-averaged density (a) and plasma fueling (b) for discharge limited on empty toroidal tray limiter.

Fig. 4 - Time evolution of the line-averaged density (a) and plasma fueling (b) for discharge with liquid lithium limiter.

Fig. $5-\mathrm{D}_{\alpha}(656.1 \mathrm{~nm})$ emission as a function of plasma current. 
Fig. 6 - OII (441.6 nm) emission as a function of plasma current. 


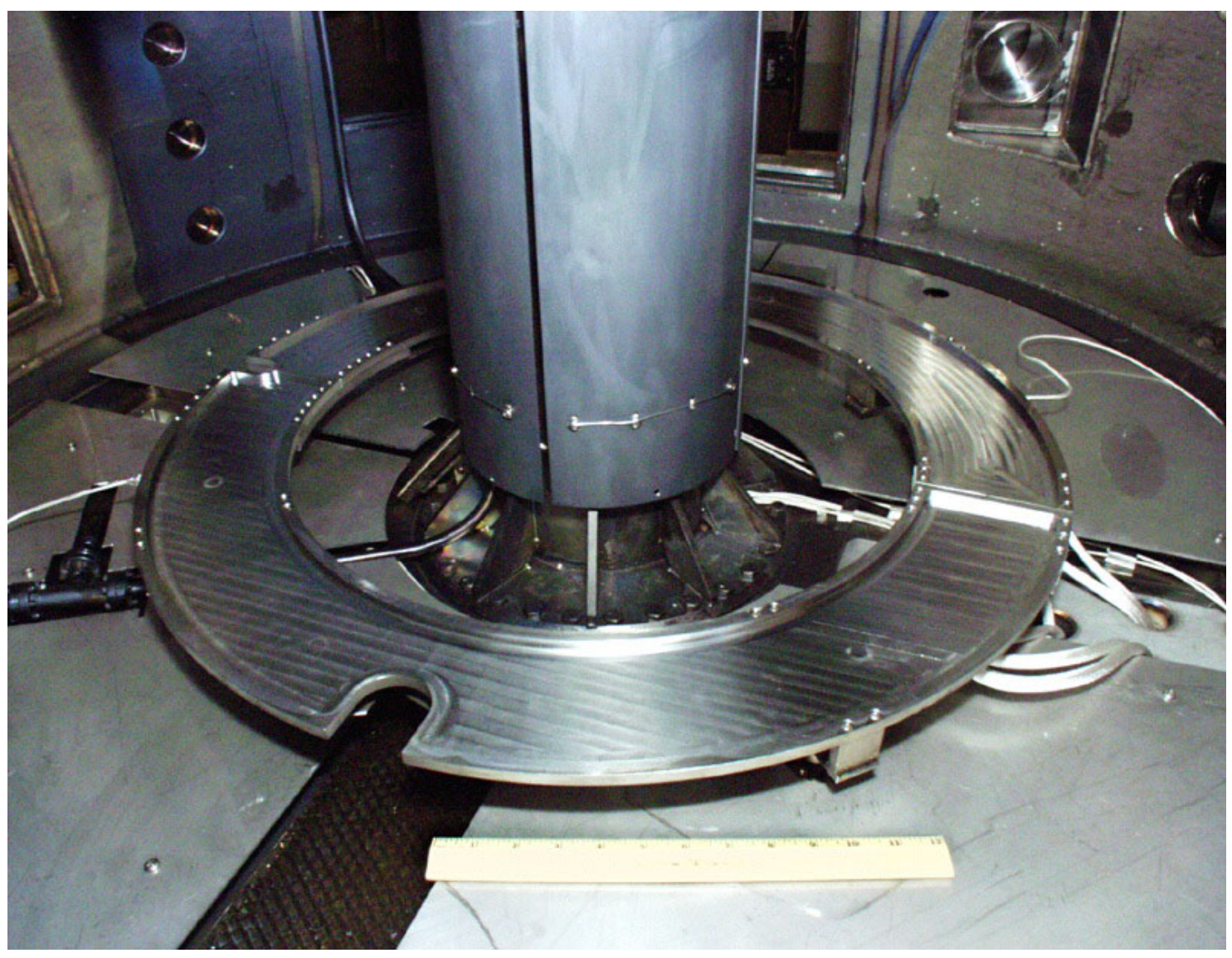

Fig. 1 


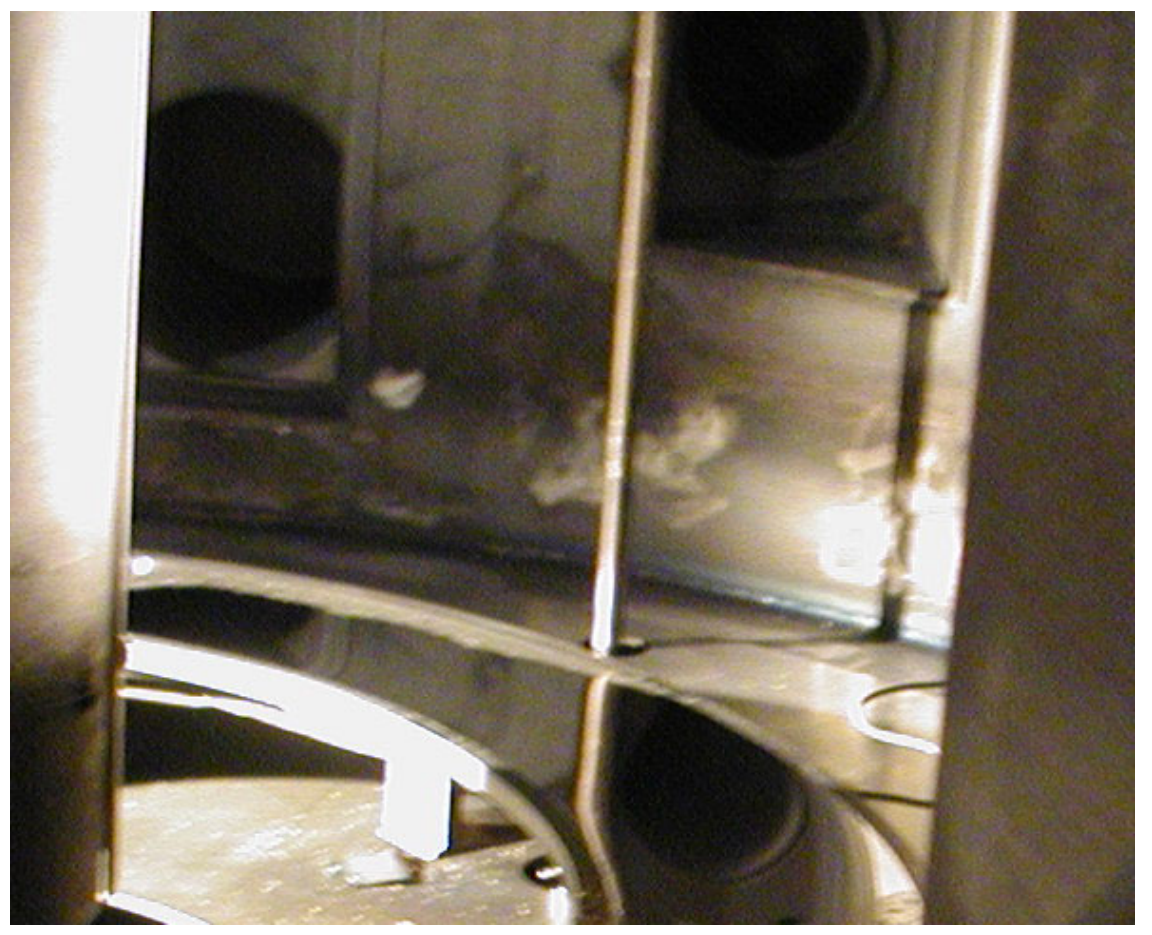

Fig. 2 

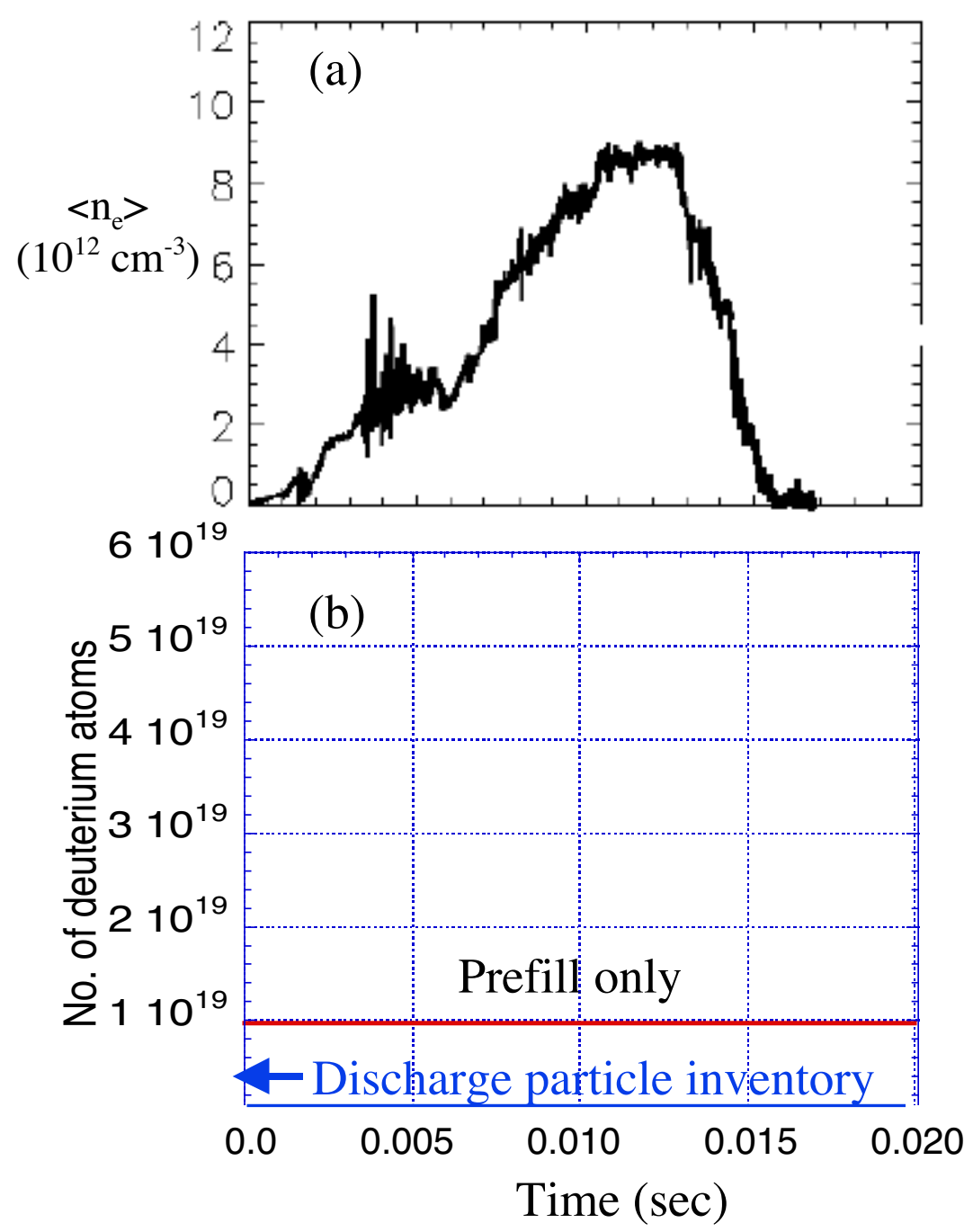

Fig. 3 


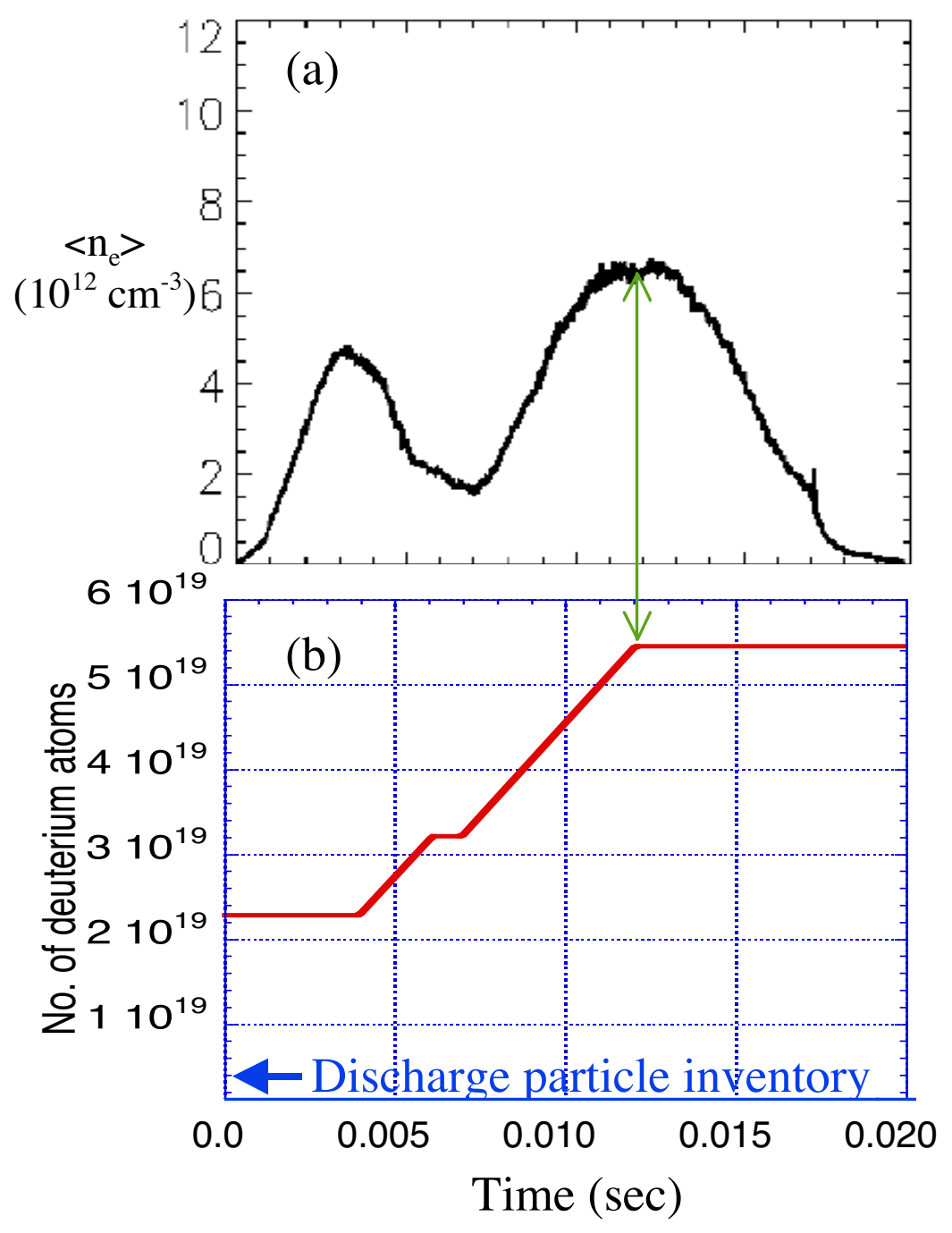

Fig. 4 


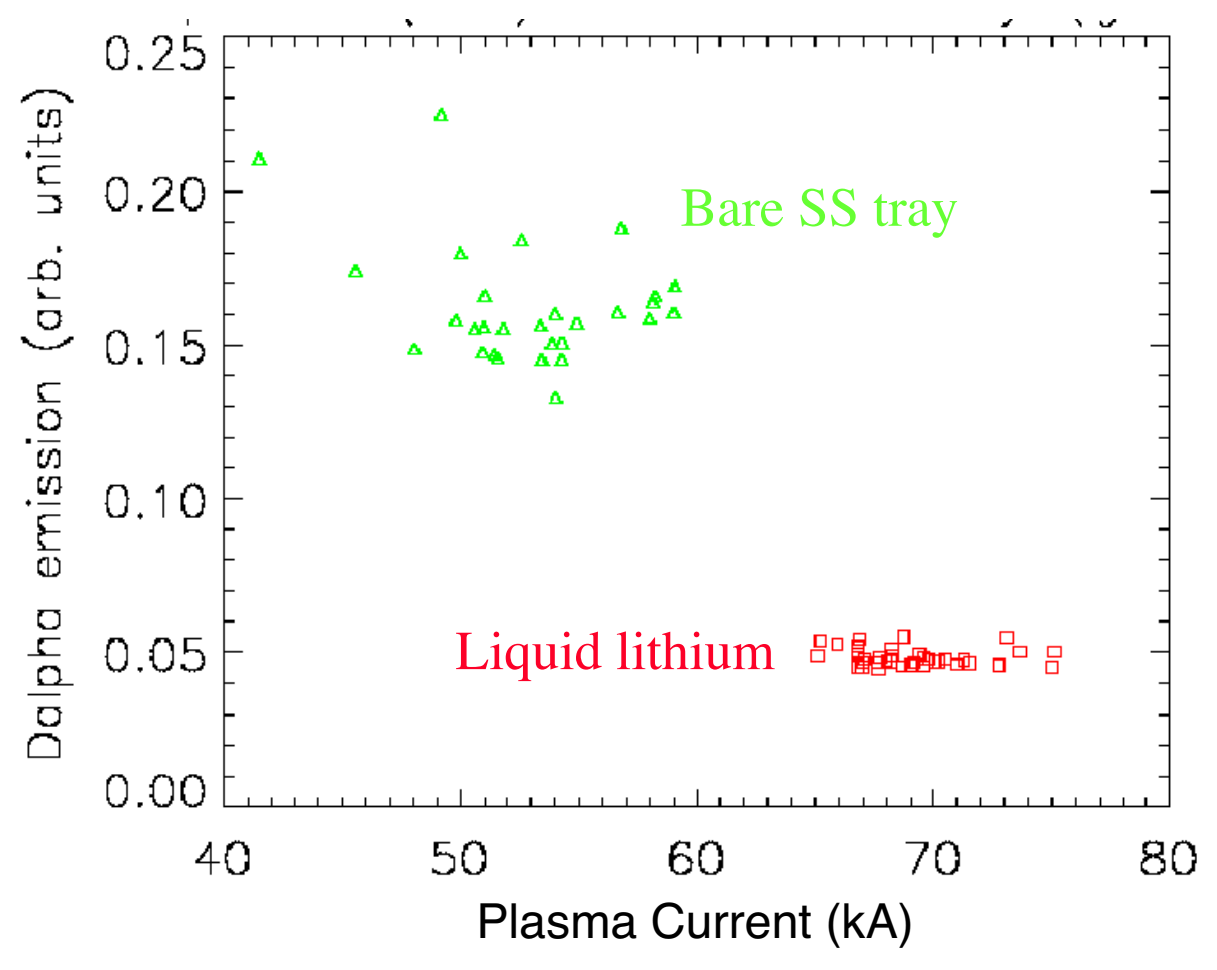

Fig. 5 


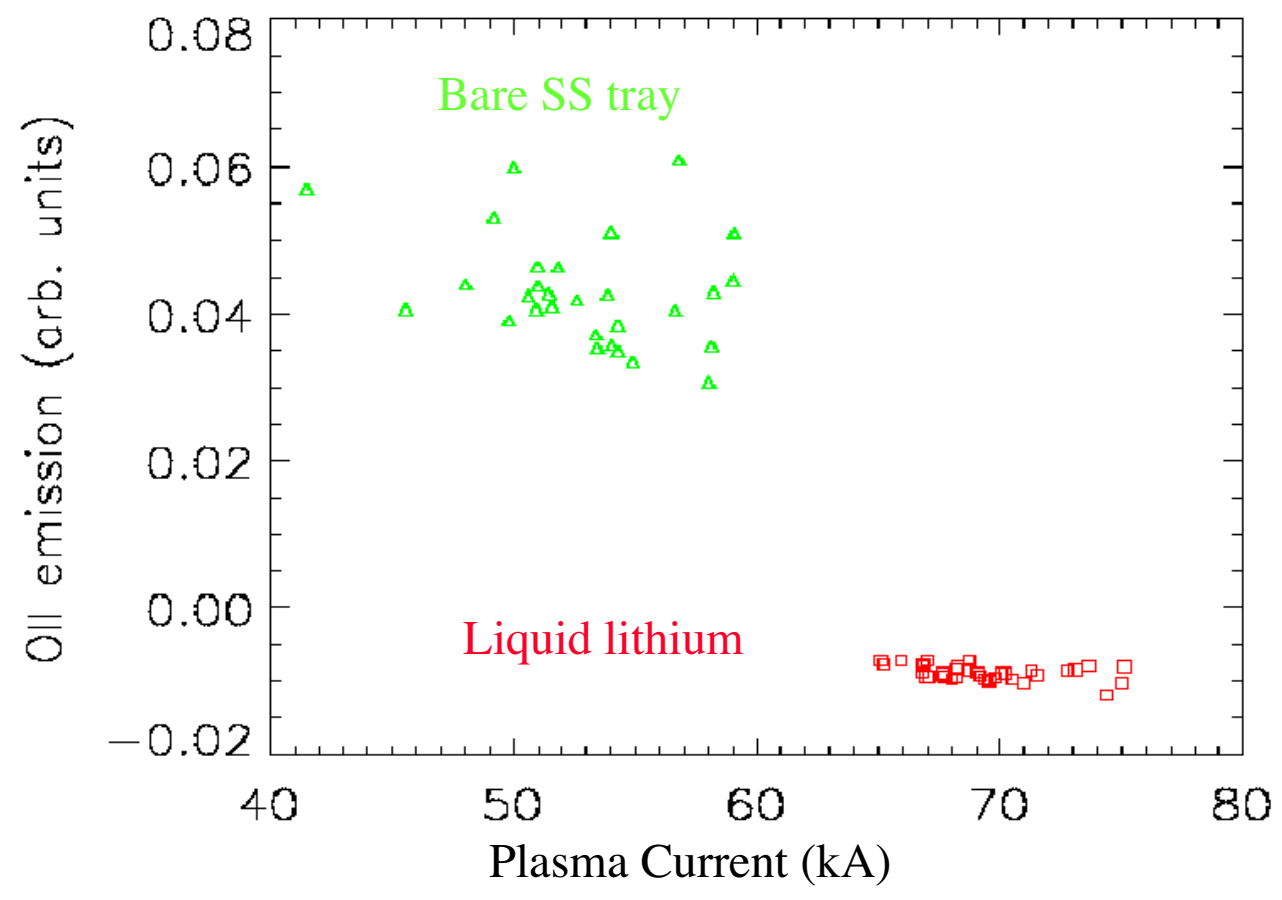

Fig. 6 
Univverilty of California

Lawrence Livermere National Laboratery

Technical Information Department

Livermore, CA 94551

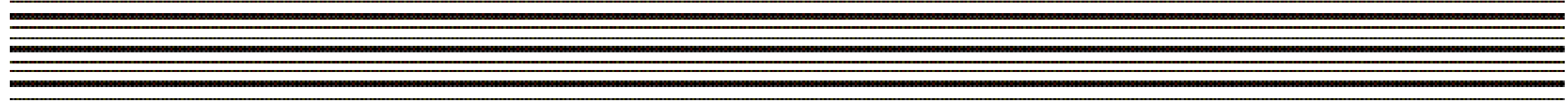

